RECORDS OF PHARMACEUTICAL
AND BIOMEDICAL SCIENCES

\title{
A Comparative study of the Clinical and Microbiological Effects of Fluoride, Xylitol and Combined Fluoride-Xylitol Toothpastes in Children
}

\author{
Samira Zakeer ${ }^{a, *}$, Rana M. Hazem ${ }^{b}$, Shaimaa OM ${ }^{b}$,Mohamed SH.SG $^{b}$, Pierre A. Hanna ${ }^{c}$ \\ ${ }^{a}$ Department of Microbiology and Immunology, Faculty of Pharmacy, Suez Canal University, Ismailia, \\ 41522, Egypt; ${ }^{b}$ Department of Pediatric and Preventive Dentistry and Dental Public Health, Faculty of \\ Dentistry, Suez Canal University, Ismailia, Egypt; ${ }^{c}$ Department of Pharmaceutics and Industrial Pharmacy, \\ Faculty of Pharmacy, Suez Canal University, Ismailia, 41522, Egypt.
}

Received on: 2-7-2021

Revised on: 19-7-2021

Accepted on: 22-7-2021

Correspondence Author:

Tel: 01092574619

E-mail address:

samirazakeer2007@hotmail.com

\begin{abstract}
The aim of our study was to evaluate and compare the clinical and microbiological efficiency of Fluoride, Xylitol and combined Fluoride Xylitol toothpastes on some salivary parameters in children by measuring salivary $\mathrm{pH}$, salivary flow rate, salivary Streptococcus mutans (S. mutans) and Lactobacillus counts. Toothpastes were prepared by mortar and pestle technique. They were then evaluated for physicochemical properties like $\mathrm{pH}$, cleanability, physical appearance, spreadability, abrasiveness, foaming power, homogeneity, content of moisture and volatile substances, and drug content. Twenty one normal apparently healthy children were selected from the Outpatient Dental Clinic of Pedodontic Department, Faculty of Dentistry, Suez Canal University. Children were randomly divided into three groups: children who brushed their teeth with fluoride toothpaste, children who brushed their teeth with xylitol toothpaste and children who brushed their teeth with combined fluoride xylitol toothpaste. Salivary samples were obtained from all groups and examined for salivary parameter changes (flow rate, $\mathrm{pH}$ ) and microbiological assessment for ( $S$. mutans and Lactobacilli) was done. All data were collected, tabled and statistically analyzed. Statistical significance was measured using $p$ value. Xylitol was superior in increasing salivary flow rate and decreasing mean of $S$. mutans when compared to fluoride while Fluoride was superior in decreasing mean of Lactobacilli when compared to xylitol. Both had the same effect on increasing salivary $\mathrm{pH}$.
\end{abstract}

Keywords: Dental caries, toothpaste, Xylitol, Fluoride, Streptococcus mutans and lactobacillus sp.

\section{Introduction:}

Dental caries is a global public health problem that influences the overall health of children (Petersen 2004). Dental plaque is formed naturally on a tooth surface as a biofilm that is embedded in a matrix of polymers of host and bacterial origin (Elamin, Garemo, and Gardner 2018; Jing et al. 2018). It is the primary etiological factor for the most frequently occurring oral diseases, such as dental caries and periodontal diseases. (Marsh 2006; Chałas et al. 2015). Prevention of dental caries can be achieved by mechanical and chemical plaque control. (Jafer et al. 2016) Mechanical plaque control requires patient cooperation and motivation; therefore, chemical plaque control is used for achieving the desired results. Hence, it is imperative for the clinicians to update their knowledge in chemical antiplaque agents and other developments for the effective 
management of plaque biofilm-associated diseases (Addy 2008; Dentino, Kassab, and Renner 2005). The use of toothpaste can provide a therapeutic effect that may have an antiplaque or anti-inflammatory basis when the nature of the agents is antimicrobial. The antiplaque activity of toothpastes is beneficial for chemical plaque control and thus prevention of dental caries (Sanz et al. 2013).

Fluoride and Xylitol are examples of antimicrobial agents which have been incorporated in toothpaste and mouth-rinse preparations to improve the outcome of mechanical oral hygiene procedures (Lippert 2013). Fluoride has been a major factor in reducing the prevalence and severity of dental caries. Topical fluoride inhibits the demineralization of sound enamel and enhances the remineralization of demineralized enamel. It also inhibits dental caries by affecting the metabolic activity of cariogenic bacteria. However, fluoride has a dose-response relationship, and improper delivery of fluoride agents may lead to fluorosis (Lagerweij and ten Cate 2002). It has been reported in many studies that fluoride alone may not be sufficient in preventing dental caries and it may not offer a complete protection against the disease and the effectiveness of fluoride could be enhanced when combined with additional cariostatic agents such as xylitol.

There has been ongoing interest in the use of sugar alcohols (Polyols) to replace traditional sugars in light of potential health benefits such as reduced carcinogenicity (Mäkinen 2010). Xylitol is a five carbon sugar alcohol and it was found that it is superior to other polyols for caries control (Van Loveren 2004). The anticariogenic effect of xylitol can be attributed to its mode of action as it cannot be fermented by oral bacteria. It reduces the acidogenic potential, increases salivary flow and inhibits cariogenic S. mutans (Janket et al. 2019).

This study was conducted to evaluate and compare the efficiency of Fluoride, Xylitol, and Combined Fluoride - Xylitol toothpastes on some salivary parameters, S.mutans and Lactobacillus sp. counts in children.

\section{Materials and methods: 2.1.Materials:}

Sodium Fluoride as well as sorbitol were purchased form Loba-Chemie ${ }^{\circledR}$, India. Xylitol was imported form Sigma-Aldrich ${ }^{\circledR}$, USA. Calcium carbonate and glycerol were purchased form Al-Gomhoria ${ }^{\circledR}$ Company for chemicals, Egypt. Sodium carboxymethyl cellulose was supplied by Merck Specialists ${ }^{\circledR}$ Pvt. Ltd., Worli, Mumbai, India. Strawberry flavor was purchased from local
Egyptian market (food grade). Red food dye FD\&C Red \#40 was supplied by Chromatech ${ }^{\circledR}$ Inc., Canton, Michigan, USA. All other chemicals were analytical grade.

\subsection{Preparation of Toothpaste:}

Toothpastes were prepared using simple mortar and pestle mixing method (Das et al. 2013). Calcium Carbonate was used as abrasive while sodium carboxymethyl cellulose was utilized as binder. In addition to active pharmaceutical principles(s) (API), a blend of calcium carbonate, sorbitol, sodium carboxymethyl cellulose solution, glycerol, red color, strawberry flavor, and water used for obtaining optimum characteristics of toothpaste (Akotakar et al. 2018). Composition of toothpastes is listed in table 1 .

All tools were sterilized prior to utilization. Each solid component was grinded solely till it was very fine, then mixing of the solid components took place in a previously sterilized mortar. The liquid components were mixed in a beaker, then, liquid ingredients were added to solid components and mixed thoroughly in an aseptic environment.

After mixing, toothpaste was packed in $5-\mathrm{ml}$ syringes for preservation in a refrigerator at $2-8^{\circ} \mathrm{C}$ before use, syringes containing the toothpaste were removed from refrigerator 3 hours prior to use, so that toothpaste was at room temperature when utilized.

\subsection{Determination of Physicochemical Properties of the Toothpastes}

The quality tests made for the evaluation of the formulated toothpastes included physicochemical controls as well as visual assessment. Assessments were done to make sure that the prepared formulations were compatible with the required standards. Each test was performed in triplicate to ensure statistical validation of the data.

\subsubsection{Determination of $\mathrm{pH}$}

The method utilized for determination of $\mathrm{pH}$ of the prepared formulation was reported by Das and coworkers with slight modification (Das et al. 2013). Simply, $2.5 \mathrm{~g}$ of the prepared formulations was placed in $250 \mathrm{~mL}$ beaker. An amount of distilled water equal to $80 \mathrm{~mL}$ was then added to the toothpaste sample. The contents of the beaker were stirred constantly for one hour to ensure complete homogeneity. The $\mathrm{pH}$ of the solution was then measured using a pre-calibrated $\mathrm{pH}$ meter. 


\subsubsection{Determination of Total Solids}

Total solids of the toothpaste are defined as the matter left after evaporation of all liquid substances (Bouassida et al. 2017). To determine total solids in the formulated toothpastes, a definite amount of the toothpaste $(1 \mathrm{~g})$ was placed in a petri dish. The sample was then heated in a hot air oven adjusted at $110^{\circ} \mathrm{C}$ for about 24 hours with frequent checking to make sure that the sample is not charring. Sample was then weighed and total solids was determined.

\subsubsection{Determination of Abrasiveness}

Abrasiveness of the prepared formulas was determined using the method reported by Das and coworkers with light modification (Das et al. 2013). Definite amount of toothpaste ( $0.5 \mathrm{gm})$ was situated on a clean and new microscopic glass slide. A drop of particulate-free distilled water was added to the sample. Using a cotton swab, the sample was rubbed on the slide in a back-and-forth motion for 25 times using short $1 \mathrm{~cm}$ stroke. The slide was, then, rinsed off carefully and dried with clean, soft tissue paper. Afterwards, the dry slide was investigated under microscope for the number of scratches present. The test was repeated three times for statistical validation of the results.

\subsubsection{Determination of Spreading Ability}

As was illustrated by many reported research papers, the ability of the toothpaste was determined using the glass slide technique (Mangilal and Ravikumar 2016; Bouassida et al. 2017).

A half gram of the toothpaste was placed on a square glass slide, each side measuring $10 \mathrm{~cm}$. Another glass slid of the same size was situated on the sample. The glass slides containing the sample in-between were carefully put under a weight of one kilogram for 10 minutes. The weight was then removed, and the mean diameter of the sample was determined and recorded in $\mathrm{cm}$.

\subsubsection{Determination of Cleaning Ability}

Eggshell was utilized in this test because of the similarity between it and human teeth due to composition of calcium compounds (King'ori 2011). The eggs were hardboiled then placed in a beaker containing $200 \mathrm{~mL}$ of boiling water to which $10 \mathrm{~g}$ of coffee, $10 \mathrm{~g}$ of tea, and $40 \mathrm{~g}$ of chocolate were added (Bouassida et al. 2017). After cooling down the hardboiled egg was placed in the staining mixture for $12 \mathrm{hrs}$ at room temperature. Excess stain on the eggshell was then removed through gentle brushing with plain wet toothbrush till consistent colour was obtained. A sample of the formula (1 gm) was tested by brushing the stained eggshell with the sample for 10 complete brush strokes.

The cleaning ability of each sample was inspected visually and the strength of cleaning ability was denoted "+++" for very powerful cleaning ability, "++" good cleaning ability, "+" mediocre cleaning ability, and "-" for bad cleaning ability (Das et al. 2013; Bouassida et al. 2017).

\subsubsection{Determination of Foaming Ability}

In test tube, $5 \mathrm{~mL}$ of double distilled water was placed, and $0.5 \mathrm{~g}$ of the toothpaste formula was added to it. The test tube was covered appropriately and vortexed for 30 seconds. The height of the produced froth and its stability were both measured (Cooper and Goldenberg 1987; Resende et al. 2019). Foaming ability was measured using the following equation (Bouassida et al. 2017):

\section{Table 1. Composition of Toothpastes}

\begin{tabular}{lllll}
\hline \multicolumn{1}{c}{ Component } & \multicolumn{1}{c}{ Function } & \multicolumn{2}{c}{ Quantities } \\
\cline { 2 - 4 } & & $\mathbf{N a F}^{\mathbf{a}}$ & $\mathbf{X I t}^{\mathbf{b}}$ & $\mathbf{N a F}^{\mathbf{b}} \mathbf{X} \mathbf{I t}^{\mathbf{c}}$ \\
\hline Sodium Carboxymethyl Cellulose & Binding agent & $0.7 \%$ & $0.7 \%$ & $0.7 \%$ \\
Sodium Fluoride & Antimicrobial Agent & $0.24 \%$ & - & $0.24 \%$ \\
Xylitol & Antimicrobial Agent & - & $10 \%$ & $10 \%$ \\
Calcium carbonate & Abrasive & $25 \%$ & $25 \%$ & $25 \%$ \\
Glycerin & Humectant & $5 \%$ & $5 \%$ & $5 \%$ \\
Sorbitol & Sweetener & $4 \%$ & $4 \%$ & $4 \%$ \\
Strawberry Flavor & Flavor and Freshness & $0.5 \%$ & $0.5 \%$ & $0.5 \%$ \\
Red dye & Appearance & $0.1 \%$ & $0.1 \%$ & $0.1 \%$ \\
\hline
\end{tabular}

a Toothpaste containing sodium fluoride as sole antimicrobial agent $(\mathrm{NaF}),{ }^{\mathrm{b}}$ toothpaste containing xylitol as sole antimicrobial agent (Xlt), ${ }^{\mathrm{c}}$ Ttoothpaste containing both sodium fluoride and xylitol as antimicrobial agents (NaF/Xlt). 
Foaming Ability $(\%)=$

$\frac{\text { The height of the foam above the water }}{\text { The total height (foam and water })} \times 100$

\subsubsection{Determination of Fineness}

The degree of fineness was determined for the toothpaste using a previously reported method (Mangilal and Ravikumar 2016). Ten grams of the prepared formula was placed in $100 \mathrm{~mL}$ glass beaker. About $50 \mathrm{~mL}$ of particle-free, distilled water was then added to the sample and stirring took place till al the sample was fully dispersed in water. The mixture was then transferred to a $150 \mu \mathrm{m}$ stainless steel sieve followed by gentle washing of the solids retaining on the sieve with water. The solids retained on the sieve were then oven-dried at $105^{\circ} \mathrm{C}$ and then weighed.

The same procedure was repeated for the same sample using a $75 \mu \mathrm{m}$ stainless steel sieve instead of $150 \mu \mathrm{m}$ one to determine the amount of degree of particles at another degree of fineness.

\subsubsection{Determination of Moisture and Volatile Substances}

On a clean dry glass watch, $5 \mathrm{~g}$ of the preparation under test was placed. The sample was dried in hot air oven at $105{ }^{\circ} \mathrm{C}$ and weight is measured periodically till no more loss in weight is detected (Mangilal and Ravikumar 2016).

The percentage of moisture and volatile substances could be calculated using the following formula:

Moisture and volatile substances $(\% \mathrm{~W} / \mathrm{W})=$ $\frac{W l}{W s} \times 100$

Where,

$W l$ is the weight loss on drying (g), and $W s$ is the weight of the sample $(\mathrm{g})$.

\subsubsection{Stability Testing}

\subsubsection{0.}

Toothpaste formulation should be stable during the whole period of shelf life. To determine the stability of toothpaste, sample is subjected to harsh conditions and physicochemical properties of the preparation was detected periodically (Bouassida et al. 2017; Mangilal and Ravikumar 2016).

Toothpaste preparation was stored in its syringe pack at $25 \pm 2^{\circ} \mathrm{C}$ for a period of 30 days (Mangilal and Ravikumar 2016). The physical properties of segregation, phase separation, fermentation, and/or gassing for the toothpaste preparation were detected (Mangilal and Ravikumar 2016). Physicochemical properties of the sample like $\mathrm{pH}$, spreading ability, and foaming ability were also detected (Bouassida et al. 2017).

Another sample was placed at $5^{\circ} \mathrm{C}$ for one hour. The sample was then extruded from the syringe and extruding behaviour of the sample was detected (Mangilal and Ravikumar 2016).

The protocol of the research project followed the guidelines of scientific committee of Suez Canal University, Faculty of Dentistry and has been approved by this committee. A brief medical and dental history and clinical examination were recorded. The procedures and steps of the study were fully explained to parents and informed written consents for treatment were obtained prior to clinical procedures. Adequate diagnosis and treatment planning were performed. Each selected child was subjected to full mouth treatment if needed till we had all the selected patients with no caries.

Children were selected from those attending Outpatient Clinic of Pediatric and Preventive Dentistry and Dental Health Department, Faculty of Dentistry, Suez Canal University from 2018-2019. Children were distributed using systematic random sampling into 3 groups: Group I included 7 children who brushed their teeth with Fluoride toothpaste, Group II included 7 children who brushed their teeth with Xylitol toothpaste and Group III included 7 children who brushed their teeth with combined Fluoride Xylitol toothpaste. Each child brushed his teeth using the simple circulatory technique (Fones method) (Muller-Bolla and Courson 2013).

For each child, Unstimulated saliva samples were collected at least 1 hour after meals (children were instructed not to eat or drink 1 hour before collection of salivary samples).The salivary samples were collected at 10 a.m. Children teeth were brushed using the given toothpaste in their respective groups for a period of $1 \mathrm{~min}(1 \mathrm{~cm}$ of each toothpaste contained the desired concentration) followed by rinsing with water $(50 \mathrm{ml})$. The children were then asked to let saliva pool in their mouth for 2 mins. and the accumulated saliva was collected for 5 mins. into sterile, labeled saliva collecting cups.

For each patient, 3 unstimulated salivary samples were collected: The first sample ( $\mathrm{Sa}$ ) was collected before using toothpaste, the second sample ( $\mathrm{Sb}$ ) was collected immediately after using toothpaste and the third one (Sc) was collected 30 minutes after using toothpaste. The toothpastes were formulated in Department of Pharmaceutics laboratory, Faculty of Pharmacy, Suez Canal University. They were prepared using simple mixing method. Calcium Carbonate was used as abrasive while sodium 
carboxy-methyl cellulose was utilized as binder. In addition to active pharmaceutical principles(s) (API), a blend of calcium carbonate, sorbitol, sodium carboxy-methyl cellulose solution, glycerol, red color (food grade), strawberry flavor (food grade) and water used for obtaining optimum characteristics of toothpaste (Akotakar et al. 2018).

Fluoride toothpaste contained $0.24 \%$ sodium fluoride for each gram (Malhotra, Singla, and Shashikiran 2017). Xylitol toothpaste contained 10\% xylitol for each gram (Shwetha and Vivek 2017) and Combined toothpaste contained mixture of both toothpastes by ratio 1:1. No preservatives were used so storage was carried out in refrigerator at a temperature ranging between $2-8^{\circ} \mathrm{C}$. The salivary flow rate was measured in the first and third samples. Children were instructed to relax for 5 minutes and swallow all saliva present in their mouths before starting saliva collection (Alkhateeb et al. 2017). While seated and leaning forward, they were told to spit all the saliva they produced into a graduated test tube through a glass funnel (Sawair et al. 2009). The unstimulated saliva collected for 5 minutes in graduated test tube was then measured by volume and expressed as milliliters per minute $(\mathrm{ml} / \mathrm{min})$ (Navazesh, Kumar, and University of Southern California School of Dentistry 2008).

The $\mathrm{pH}$ of the whole saliva was measured in in the three salivary samples using color coded $\mathrm{pH}$ Strips $\left(\right.$ Merck $^{\circledR}$, Germany). Bacterial counts were measured in the three salivary samples. The samples were preserved in an ice box then taken immediately to the laboratory of Department of Microbiology, Faculty of Pharmacy, Suez Canal University. Mitis salivarius bacitracin agar for $S$. mutans and Rogosa agar for Lactobacillus $s p$ were previously prepared according to manufacturer instructions in petri dishes and kept in the refrigerator to be ready for use. Anaerobic Gas-Pack system was kept ready just before the saliva samples arrived in the laboratory.

All procedures were done under aseptic conditions to avoid contamination of the samples. Samples from each patient were given the letters a, $\mathrm{b}, \& \mathrm{c}$ respectively ( $\mathrm{Sa}, \mathrm{Sb}$ and $\mathrm{Sc}$ ). The number of patient was written on each of them such as (1a, 1b and 1c).

For each patient, 9 Wasserman tubes were filled with 900 microliters of sterile saline solution using sterile micropipette to do tenfold serial dilutions needed (serial dilutions of saliva were made up to $10^{-3}$, before plating). Three dilutions for each sample were done and these tubes were labeled with the number of patient, number of sample and the dilution inside it such as $\left(1 \mathrm{a} 10^{-1}, 1 \mathrm{a} 10^{-2}, 1 \mathrm{a} 10^{-3}\right)$.
Each petri-plate was divided into 4 sectors using a marker, three sectors for the three dilutions and the forth one for the original sample. $10 \mu \mathrm{l}$ from the original sample was spread evenly on the $1^{\text {st }}$ sector of the petri-plate, $10 \mu \mathrm{l}$ from the $1^{\text {st }}$ dilution on the $2^{\text {nd }}$ sector, $10 \mu \mathrm{l}$ from the $2^{\text {nd }}$ dilution on the $3^{\text {rd }}$ sector, $10 \mu \mathrm{l}$ from the $3^{\text {rd }}$ dilution on the last one. This was repeated for all samples for all patients.

The plates were sealed, placed in an anaerobic jar with Gas Pack system (Thermo scientific ${ }^{\circledR}$, USA) and incubated at $37^{\circ} \mathrm{C}$ for 48 hours. Colony counting was done under a colony counter and the number of CFU were multiplied by the number of times the original $\mathrm{mL}$ of sample was diluted (the dilution factor of the plate counted) and expressed as the number of colony forming units per milliliter (CFU/mL) of saliva (Hegde and Kamath 2017).

$\mathrm{CFU} / \mathrm{ml}=$ (no. of colonies $\mathrm{x}$ dilution factor $)$ / inoculum size

After taking the needed amounts from saliva samples for bacteriological measurements, $\mathrm{pH}$ strips were inserted in the samples to measure salivary $\mathrm{pH}$. Data were collected, compared then statistically analyzed. Numerical data were explored for normality by checking the distribution of data and using tests of normality (Kolmogorov-Smirnov and Shapiro-Wilk tests).

\section{Results:}

\subsection{Physical characteristics of the prepared formula}

It was clearly demonstrated by figure 1 that the visual properties of the prepared toothpaste were accepted for use by children. The visual inspection of the prepared formula revealed many characteristics that are listed in table 2.

Table 2. Physical Characteristics of Toothpaste.

\begin{tabular}{|l|l|}
\hline Item & Value \\
\hline Color & Red \\
\hline Odor & Strawberry \\
\hline Flavor & Strawberry \\
\hline Taste & Sweet \\
\hline Smoothness & Smooth \\
\hline Homogeneity & Homogenous \\
\hline Elegancy & Aesthetic Appearance \\
\hline
\end{tabular}

\subsection{Physicochemical Characteristics of The Prepared Toothpastes:}

Physicochemical characteristics of the toothpastes 


\section{Zakeer et al.}

were listed in table 3 . It was clearly illustrated that the $\mathrm{pH}$ of the prepared formulations was around 7.5 which is very slightly alkaline. Number of scratches in abrasiveness test showed the toothpaste to be not harmful on the enamel and dentin of the patients due to its particles being well pulverized and ground to a very fine degree. The toothpaste was shown to have a very good cleaning ability with minimum degree of foaming as compared to many commercial products from many countries (Cooper and Goldenberg 1987; Mangilal and Ravikumar 2016; Bouassida et al. 2017; Resende et al. 2019).

In general, the prepared toothpaste formulations were shown to be accepted for use by children and to be useful with no harm on their teeth.

\subsection{Stability of preparations}

Stability testing results were shown in table 4 . As it was clearly illustrated that inspection of the formulations after 30 days of storage at $25^{\circ} \mathrm{C}$ and
Rec. Pharm. Biomed. Sci. 5 (2), 100-114, 2021

$5^{\circ} \mathrm{C}$ revealed no segregation of particles, no phase separation of the solid and liquid phases, and no fermentation or gassing happened. This indicates that formulations were prepared under sanitary conditions which prevented contamination of the formulation. Also, particles were thoroughly and perfectly mixed with liquid phases; and the liquid phase was chosen very carefully so that no segregation or phase separation took place.

Regarding physicochemical measurement after storage for 30 days at room temperature and in refrigerator, it was demonstrated clearly that after 30 days, values of physicochemical parameters showed very slight change that was not statistically different from the immediately measured values. This illustrates the high stability of the prepared toothpaste formulations.

Storage at $25^{\circ} \mathrm{C}$ and $5^{\circ} \mathrm{C}$ showed that temperature had minimal effect on the stability of the prepared formulations, if any.

Table 3. Physicochemical Characteristics of Toothpaste.

\begin{tabular}{llll}
\hline Item & $\begin{array}{l}\text { Xylitol } \\
\text { Toothpaste }\end{array}$ & $\begin{array}{l}\text { Sodium Fluoride } \\
\text { Toothpaste }\end{array}$ & $\begin{array}{l}\text { Sodium } \\
\text { Fluoride/Xylitol } \\
\text { Toothpaste }\end{array}$ \\
\hline $\mathrm{pH}$ & $7.54 \pm 0.12$ & $7.68 \pm 0.3$ & $7.71 \pm 0.28$ \\
Total Solids (\%) & $42.6 \pm 1.9$ & $31.9 \pm 1.5$ & $42.8 \pm 1.3$ \\
Abrasiveness (Scratches) & 2 & 1 & 2 \\
Spreading Ability (cm) & $2.8 \pm 0.2$ & $3.1 \pm 0.3$ & $2.7 \pm 0.4$ \\
Cleaning Ability & +++ & +++ & +++ \\
Foaming Ability (\%) & $17.2 \pm 1.8$ & $20.9 \pm 2.3$ & $22.1 \pm 1.9$ \\
Fineness (150 $\mu \mathrm{m})$ & $37.1 \pm 2.4$ & $41.5 \pm 3.3$ & $39.8 \pm 3.7$ \\
Fineness (75 $\mu \mathrm{m})$ & $49.2 \pm 2.4$ & $47.6 \pm 1.7$ & $50.9 \pm 2.8$ \\
Moisture and Volatile & $46.3 \pm 3.1$ & $54.4 \pm 2.9$ & $45.8 \pm 2.7$ \\
Substances & & & \\
\hline
\end{tabular}

Table 4. Physicochemical Characteristics of Toothpaste immediately after preparation and after $\mathbf{3 0}$ days of preparation.

\begin{tabular}{|c|c|c|c|c|c|c|c|c|c|}
\hline & \multicolumn{3}{|c|}{ Xylitol Toothpaste } & \multicolumn{3}{|c|}{ Sodium Fluoride Toothpaste } & \multicolumn{3}{|c|}{ Sodium Fluoride/Xylitol Toothpaste } \\
\hline & Immediate & $\begin{array}{l}\text { After } 30 \\
\text { Days } \\
\left(25^{\circ} \mathrm{C}\right)\end{array}$ & $\begin{array}{l}\text { After } 30 \\
\text { Days } \\
\left(5^{\circ} \mathrm{C}\right)\end{array}$ & Immediate & $\begin{array}{l}\text { After } 30 \\
\text { Days } \\
\left(25^{\circ} \mathrm{C}\right)\end{array}$ & $\begin{array}{l}\text { After } 30 \\
\text { Days } \\
\left(5^{\circ} \mathrm{C}\right)\end{array}$ & Immediate & $\begin{array}{l}\text { After } 30 \\
\text { Days } \\
\left(25^{\circ} \mathrm{C}\right)\end{array}$ & $\begin{array}{l}\text { After } 30 \\
\text { Days } \\
\left(5^{\circ} \mathrm{C}\right)\end{array}$ \\
\hline Segregation & - & - & - & - & - & - & - & - & - \\
\hline $\begin{array}{l}\text { Phase } \\
\text { Separation }\end{array}$ & - & - & - & - & - & - & - & - & - \\
\hline $\begin{array}{l}\text { Fermentation } \\
\text { gassing }\end{array}$ & - & - & - & - & - & - & - & - & - \\
\hline $\mathrm{pH}$ & $7.54 \pm 0.12$ & $\begin{array}{l}7.46 \pm \\
0.21\end{array}$ & $\begin{array}{l}7.49 \pm \\
0.30\end{array}$ & $7.68 \pm 0.30$ & $\begin{array}{l}7.63 \pm \\
0.27\end{array}$ & $\begin{array}{l}7.66 \pm \\
0.35\end{array}$ & $7.74 \pm 0.31$ & $\begin{array}{l}7.69 \pm \\
0.22\end{array}$ & $\begin{array}{l}7.72 \pm \\
0.37\end{array}$ \\
\hline $\begin{array}{l}\text { Spreading } \\
\text { Ability }(\mathrm{cm})\end{array}$ & $2.8 \pm 0.2$ & $2.7 \pm 0.3$ & $2.8 \pm 0.1$ & $3.1 \pm 0.3$ & $2.9 \pm 0.1$ & $2.9 \pm 0.4$ & $2.7 \pm 0.4$ & $2.6 \pm 0.2$ & $2.8 \pm 0.3$ \\
\hline $\begin{array}{l}\text { Cleaning } \\
\text { Ability }\end{array}$ & H+ & H+ & $+H$ & H & $H+$ & $H+$ & H+ & H+ & H \\
\hline $\begin{array}{l}\text { Foaming Ability } \\
(\%)\end{array}$ & $17.2 \pm 1.8$ & $\begin{array}{l}17.3 \pm \\
2.1\end{array}$ & $\begin{array}{l}16.8 \pm \\
1.7\end{array}$ & $20.9 \pm 2.3$ & $20.2 \pm 1.6$ & $\begin{array}{l}20.4 \pm \\
2.8\end{array}$ & $22.1 \pm 1.9$ & $23.4 \pm 3.1$ & $\begin{array}{l}21.5 \pm \\
2.7\end{array}$ \\
\hline
\end{tabular}


In comparison of salivary flow rate between the three groups, as shown in figure 1, there was nonsignificant increase in flow rate when comparing group I with group II and group III before using toothpaste $(\mathrm{P}=0.153)$. However, when comparing the 3 groups after 30 mins. from using toothpaste, there was a significant increase in flow rate (significant for xylitol) $(\mathrm{P}=0.04)$

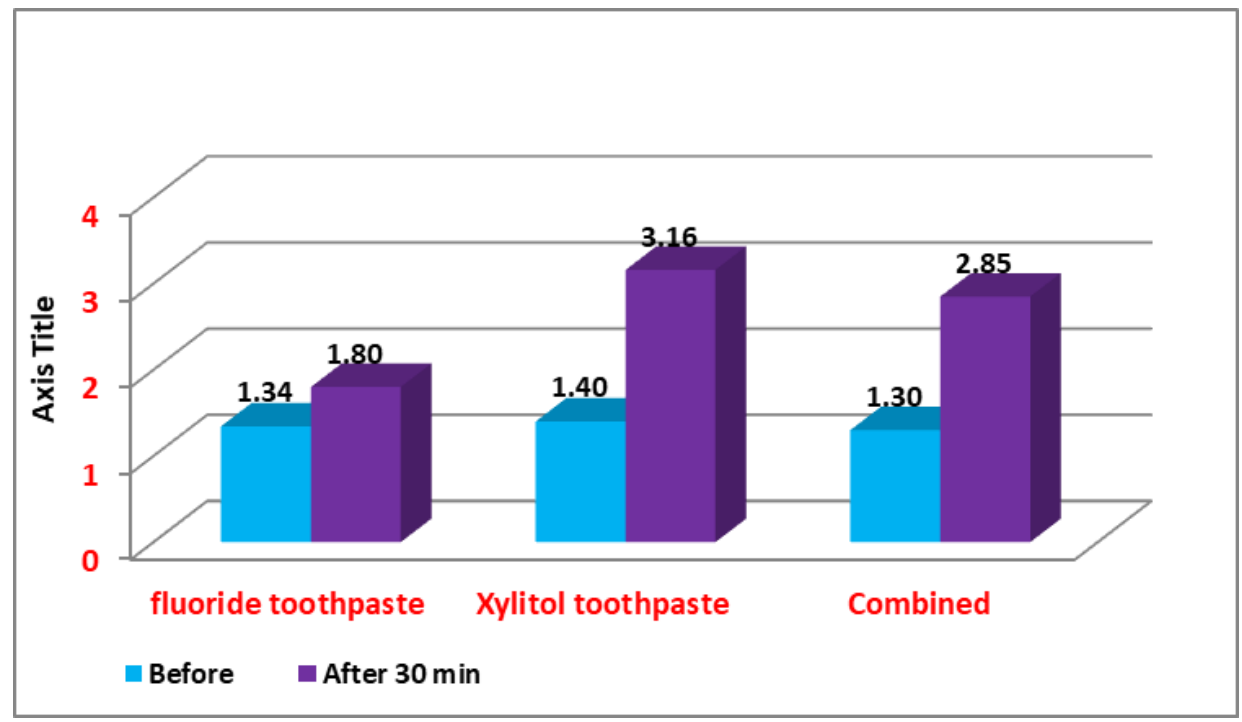

Figure 1. Salivary flow rates mean before and 30 mins. after toothpaste use in the three study groups

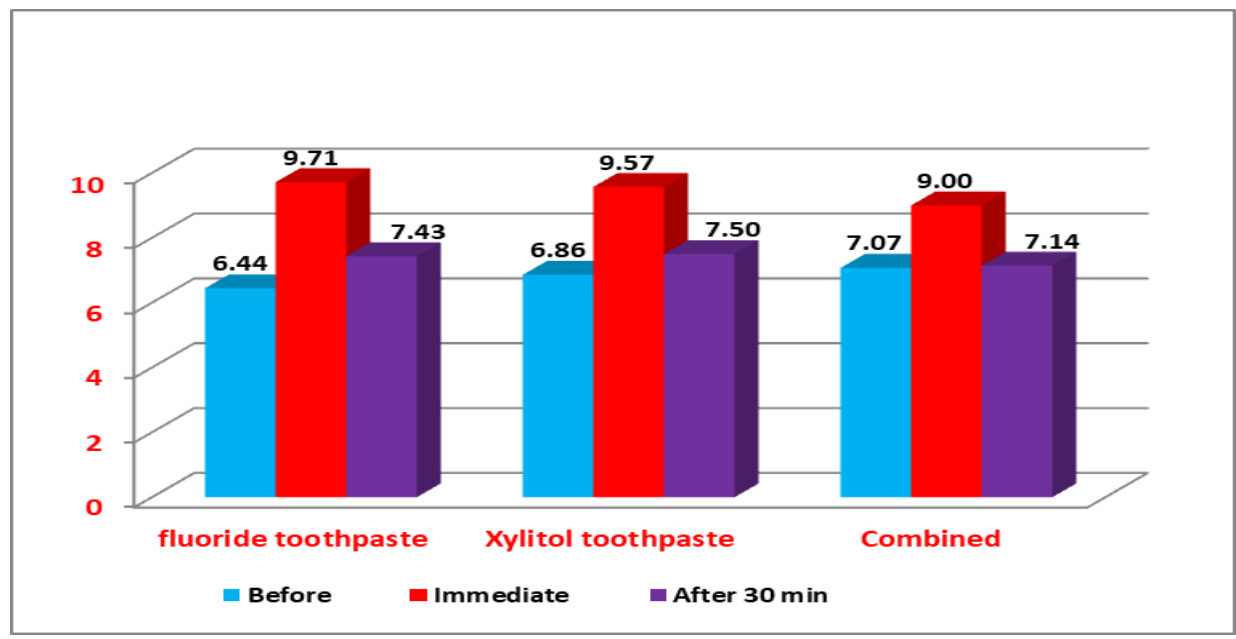

Figure 2. Salivary pH mean changes in the three study groups.

Figure 2 showed that upon comparing salivary $\mathrm{pH}$ in the three groups, there was non-significant increase when comparing group I with group II and group III before using toothpaste $(\mathrm{P}=0.185)$, immediately after using toothpaste $(\mathrm{P}=0.108)$ and 30 mins. after using toothpaste $(\mathrm{P}=0.429)$. In comparison of $S$. mutans count between the 3 groups, there was nonsignificant difference between them before using toothpaste $(\mathrm{P}=0.8933)$. However, when comparing the 3 groups immediately after using toothpaste, there was a highly significant decrease towards group III from $153.31 \times 10^{3} \mathrm{CFU}$ in group I to $79.71 \times 10^{3} \mathrm{CFU}$ in group III ( $\left.\mathrm{P}=0.0005\right)$.Moreover, when comparing the 3 groups after 30 mins. from using toothpaste, there was a highly significant decrease in the bacterial count towards group III from $147.93 \times 10^{3} \mathrm{CFU}$ in group I to $41.08 \times 10^{3} \mathrm{CFU}$ in group III $(\mathrm{P}=0.000)$. This was clearly illustrated by figure 3 . Figure 4 illustrated that when comparing the Lactobacillus sp. count in the three groups, 
there was no significant difference between them before using toothpaste $(\mathrm{P}=0.7910)$. However, when comparing the three groups immediately after using toothpaste, the bacterial count in group III was $860.71 \times 10^{3}$ CFU which was highly significantly decreased when compared to group I and group II
$(\mathrm{P}=0.0028)$ and when comparing the three groups after 30 mins. from using toothpaste, the bacterial count in group III was $553.57 \times 10^{3} \mathrm{CFU}$ which was highly significantly decreased when compared to group I and group II ( $\mathrm{P}=0.000)$.

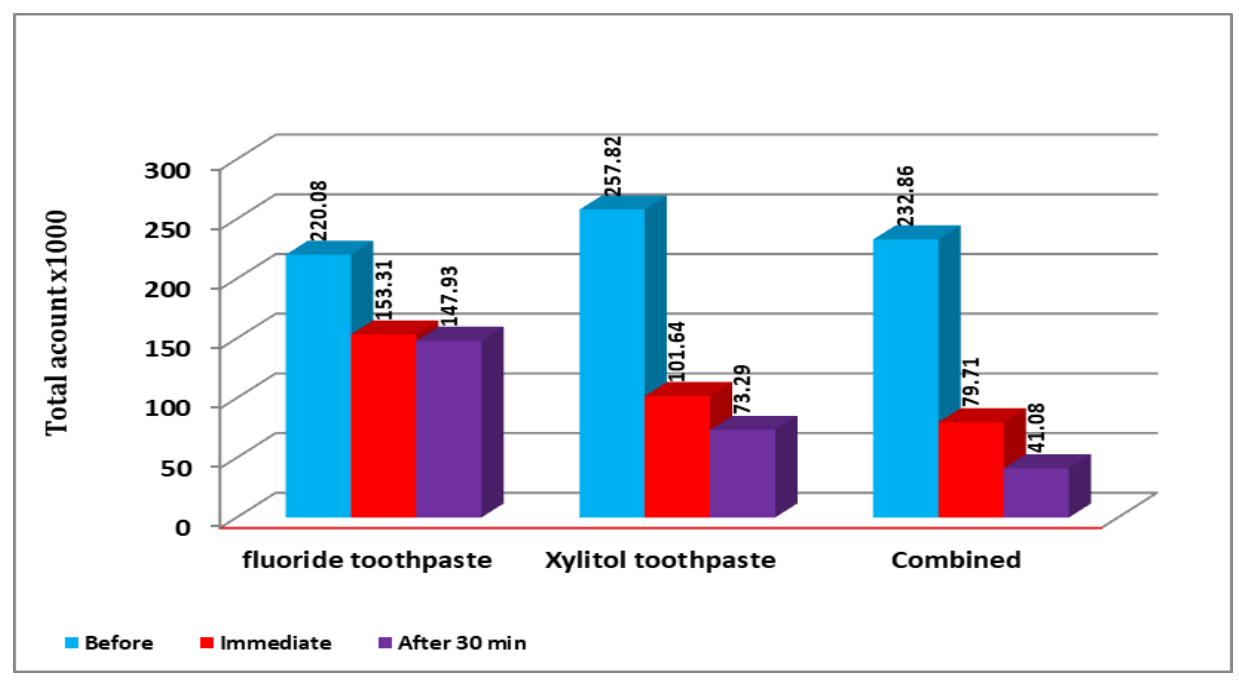

Figure 3. Streptococcus mutans mean count in the three study groups

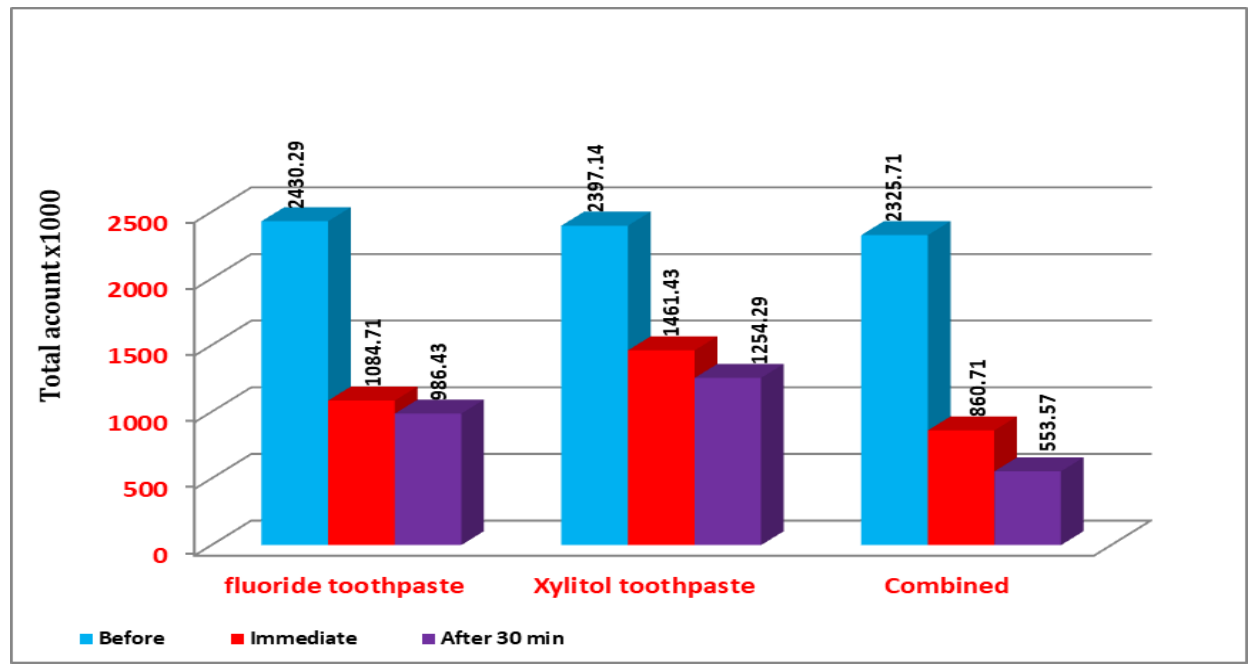

Figure 4. Lactobacillus sp. mean count in the three study groups

\section{Discussion:}

A total of 21 apparently healthy children with the age group of 3-6 years of both sexes were selected from Outpatient Dental Clinic of Pedodontic Department, Faculty of Dentistry, Suez Canal University according to inclusion and exclusion criteria. This age was selected due to high susceptibility to dental caries. The circular brushing technique (Fones technique) was used for each patient for easy removal of dental plaque. This was in agreement with Simratvir et al, 2009 (Simratvir et al. 2009) and Chandan et al, 2018 (Chandan et al. 2018) who selected the same age group in their studies. All 
children were examined clinically for detection of any carious lesions and they had received full mouth treatment before starting the procedures to have no external factors that may affect the accuracy of the results (Sabri et al. 2020). Toothpastes were used because they are important means of chemical plaque control (Hosadurga et al. 2018). Fluoride was used in this study in accordance to Arnold et al, 2006 (Arnold et al. 2006) and da Camara et al, 2014 (da Camara et al. 2014) who have conducted their studies on fluoride toothpaste. Fluoride has an important role in prevention of dental caries, it is beneficial to all age groups throughout their life. Xylitol toothpaste was used in this study due to its benefits in the dental field. The AAPD recognized that there is considerable research on sugar substitutes, particularly xylitol, and their potential oral health benefits for infants, children and adolescents (Fraga, Mayer, and Rodrigues 2010). Chi and co-workers conducted their study on xylitol toothpaste for prevention of ECC and reported that xylitol cannot be fermented by most bacteria in the oral cavity (Chi, Tut, and Milgrom 2014).

A combination of fluoride and xylitol toothpaste was used to assess the benefits of them together as it was found in some studies that fluoride by itself is not a potent antimicrobial agent and there is a need to add some chemical agents to it so as to improve its effect such as xylitol as recommended by some guidelines for prevention of dental caries especially in high caries risk individuals (Pinar Erdem et al. 2012). The whole unstimulated saliva was collected from all children as it is noninvasive technique and easy performed particularly in pediatric populations (Bhattarai, Kim, and Chae 2018). This was in agreement with $\mathrm{Wu}$ et al (Wu et al. 2008) and Kuriakose et al, 2013 (Kuriakose et al. 2013) as they measured unstimulated saliva in their studies. In salivary diagnostics, unstimulated saliva is often preferred to the stimulated whole saliva, since the latter contains only a diluted concentration of biomarkers that may be difficult to detect ( $\mathrm{K}$ and $\mathrm{K}$ 2021).

Salivary samples were collected in the early morning to avoid diurnal variations from participants and to minimize circadian rhythm effects (Flink, Tegelberg, and Lagerlöf 2005). They were collected and preserved in an ice box to maintain their stability (Esser et al. 2008) then immediately transferred to the laboratory of microbiology, Faculty of Pharmacy, Suez Canal University to avoid any changes in the components of salivary samples (Den et al. 2007). Salivary flow rate was measured as it helps in lubrication \& reducing incidence of dental caries. It is a good indicator for salivary functions and salivary diseases which may increase the risk for caries development (Alves et al. 2010).

Salivary $\mathrm{pH}$ was also measured as it is an important salivary diagnostic biomarker. It can be considered as an indicator for caries risk. Demineralization and remineralization processes of the teeth, occurring in the oral cavity are dependent on the $\mathrm{pH}$ of the saliva. The saliva is rich in calcium and phosphates and is nearly always supersaturated with respect to enamel minerals and other biological appetites. The alkaline $\mathrm{pH}$ of the saliva neutralizes the acid produced by the plaque bacteria. The more basic is the $\mathrm{pH}$ of the saliva more is the remineralization of tooth surface by the precipitation of bicarbonate ions (Baliga, Muglikar, and Kale 2013).

In this study, there was no statistically significant difference in the mean salivary flow rate between the three groups at baseline. There was a significant increase in salivary flow rate in group I after $30 \mathrm{~min}$ from using fluoride toothpaste in comparison to baseline measurement. This was in agreement with Ingle and co-workers (Ingle et al. 2014) who measured salivary fluoride levels after tooth brushing with dentifrices containing different concentrations of fluoride in children. Saliva samples were collected prior to brushing, immediately after brushing, and at intervals of 15 , 30 , and $60 \mathrm{~min}$. salivary flow rate increased significantly after 15 and $30 \mathrm{~min}$ but after $60 \mathrm{~min}$ it was none significantly increased. This may be due to increased fluoride concentration in saliva after using fluoride toothpaste which has an anticariogenic effect. This agrees with Campus et al, (Campus, Lallai, and Carboni 2003).who concluded that the fluoride concentration in saliva could be maintained to an optimal therapeutic level with the regular use of fluoridated products.

Xylitol toothpaste highly significantly increased salivary flow rate after 30 mins. from using it when compared to baseline measurement. This was in agreement with Pancu and co-workers (Pancu et al. 2017) who conducted a study on xylitol-based oral hygiene products (toothpastes, mouthwashes and chewing gums) to evaluate their effect on salivary parameters and there was a significant increase in salivary flow rate after three weeks of xylitol-based products consuming.

Moreover, there was a highly significant increase in salivary flow rate after 30 mins. from using the combined fluoride xylitol toothpaste when compared to xylitol treated group and fluoride treated group. This increase may be attributed to xylitol as it may decrease lactic acid production, 
increase salivary flow potentially leading to an increased buffering of acids in plaque (Hayes 2001). These results concluded that there is no strong synergistic effect of fluoride with xylitol on salivary flow rate.

The results proved that there was a highly significant increase in salivary $\mathrm{pH}$ in the fluoride group immediately after using toothpaste when compared to $\mathrm{pH}$ at baseline in the same group. This may be due to increased concentration of fluoride in dental biofilm immediately after using fluoride dentifrice (Souza, Maltz, and Hashizume 2014). Then pH decreased significantly after 30 mins. from using toothpaste when compared to the immediate salivary $\mathrm{pH}$. It was in agreement with Advani and co-workers (Advani et al. 2014) who evaluated the effect of different pediatric fluoride dentifrices on artificial carious lesions in primary teeth and they found that there was increase in salivary $\mathrm{PH}$ with using fluoride dentifrices. The decrease in salivary $\mathrm{pH}$ after 30 mins. from using fluoride toothpaste may be due to decreased fluoride retention in the oral cavity. Sotthipoka et al., (Sotthipoka et al. 2018) studied the effects of toothpaste amounts and post-brushing rinsing methods on salivary fluoride retention. They stated that fluoride concentration increased from the baseline to the highest concentration at time 0 (immediately) then dramatically decreased within 10 min.

There was a highly significant increase in salivary $\mathrm{pH}$ immediately after using xylitol toothpaste then $\mathrm{pH}$ decreased significantly after 30 mins. from using toothpaste when compared to the immediate salivary $\mathrm{pH}$ in the same group. This agrees with a previously reported researches (Muralikrishnan, Asokan, and Priya 2018). The xylitol mode of action includes absence of significant degradation into acidic endproducts by dental plaque, stimulation of salivary flow and increased buffering capacity, inhibition of plaque accumulation and of cariogenic bacteria (da Camara et al. 2014). This could explain the immediate increase in salivary $\mathrm{pH}$ after using xylitol toothpaste.

Also, there was a highly significant increase in salivary $\mathrm{pH}$ in the combined fluoride xylitol group immediately after using toothpaste then decreased significantly after 30 mins. from using toothpaste when compared to the immediate salivary $\mathrm{pH}$ in the same group. This means that adding xylitol to fluoride does not have a strong synergistic effect on salivary $\mathrm{pH}$. The results of the current study revealed that there was a highly significant decrease in the mean of $S$. mutans count immediately after using fluoride toothpaste when compared to the baseline count then the bacterial count none significantly decreased after 30 mins. from using toothpaste when compared to the immediate count.

The decrease in S. mutans count with fluoride toothpaste may be due to the mode of action of fluoride as it helps in inhibition of ATPase production causing intracellular cytoplasmic acidification via the inhibition of proton outflux from the bacterial cell. This leads to inhibition of acid production and limit the $\mathrm{pH}$ drop within bacterial biofilms (Fraga, Mayer, and Rodrigues 2010). It was proven that $\mathrm{NaF}$ significantly decreased bacterial counts immediately and after 30 mins. when compared to baseline but after 120 mins., the bacterial count returned to baseline so they concluded that $\mathrm{NaF}$ products showed a short term increase in fluoride bioavailability with significant decreases in the bacterial viability of different oral surfaces (Chi, Tut, and Milgrom 2014).

There was a highly significant decrease in S.mutans count immediately in the xylitol group when compared to baseline. After 30 mins. from using xylitol toothpaste, the bacterial count continued to decrease significantly when compared to baseline and the immediate count after using xylitol toothpaste. This was in agreement with Pinar Erdem et al. who have conducted a study to assess the effects of xylitol mouth rinse on S.mutans counts and found significant reductions in the scores of $S$. mutans after the four week use of xylitol mouth rinse (Pinar Erdem et al. 2012). The significant reduction in the $S$. mutans count after 30 mins. from using xylitol toothpaste may be an indicator of the longterm antibacterial effect of xylitol (Bhattarai, Kim, and Chae 2018). The antibacterial effect of xylitol was explained in many studies as it disrupts the energy production processes of $S$. mutans leading to a futile energy consumption cycle and cell death (Wu et al. 2008).

Also, there was a highly significant decrease in $S$. mutans count in group III immediately after using the combined fluoride xylitol toothpaste when compared to baseline then continued to decrease significantly after 30 mins. from using toothpaste when compared to baseline and the immediate count. It was previously reported that the combined fluoride xylitol toothpaste had influence on the decrease of the number of $S$. mutans in saliva and the increase of $\mathrm{pH}$ value. They concluded that when xylitol added to the toothpastes, it has a positive influence on the quality of the oral environment (Kuriakose et al. 2013).

There was a highly significant decrease in the mean 
count of Lactobacilli immediately after using fluoride toothpaste when compared to baseline in the same group then the bacterial count continued to decrease none significantly after 30 mins. from using fluoride toothpaste when compared to the immediate count. Upon studying the effects of fluoridated dentifrice and oral health program on the oral health status of visually impaired children. The Lactobacilli counts were assessed at baseline, immediately after treatment and at 3,6 and 12 months intervals and they found that at the end of 3,6,12 months there was a significant decrease in fluoridated group as compared to the non-fluoridated (Kumar et al. 2012). On the other hand, Akihiro Yoshihara and coworkers studied the long term use of fluoride mouth rinse on the salivary levels of $S$. mutans and Lactobacilli and suggested that fluoride mouth rinse did not affect the levels of Lactobacilli (Yoshihara et al. 2001).

There was a highly significant decrease in the Lactobacilli count immediately after using xylitol toothpaste when compared to baseline then the bacterial count none significantly decreased after 30 mins. from using the toothpaste when compared to the immediate count. This disagrees with other reported researches who concluded in their studies that xylitol had no significant effect on Lactobacilli counts (Caglar et al. 2007; Oza et al. 2018). The significant decrease in the Lactobacilli count in this study may be explained as xylitol induces elevation of the oral $\mathrm{pH}$ and thus may have an indirect effect on Lactobacilli as was illustrated by Mäkinen et al who studied the effects of xylitol on salivary and plaque levels of S.mutans and the salivary levels of aerobically cultured aciduric bacteria (mostly representing Lactobacilli) and they found that there was statistically significant reduction in the scores of both microorganisms and concluded that long term use of xylitol containing chewing gum can reduce the growth of S.mutans and Lactobacilli-type bacteria in saliva (Mäkinen et al. 2008).

There was also a highly significant decrease in the mean count of Lactobacilli immediately after using the combined fluoride xylitol toothpaste when compared to baseline then the bacterial count significantly decreased after 30 mins. from using the toothpaste when compared to baseline and the immediate count. This was in agreement with HrvojeJurić et al who found that the paste containing fluoride and xylitol had the greatest antibacterial effect against Lactobacilli (Juri and Ukovi 2011).

\section{Conclusion:}

In this study, it was concluded that xylitol stimulates salivary flow rate more than fluoride and it has a superior antibacterial effect against salivary S.mutans when compared to fluoride. Xylitol and fluoride have the same effect on salivary $\mathrm{pH}$. Fluoride has a superior effect against salivary Lactobacilli when compared to xylitol. Using a combination of fluoride and xylitol provides a synergistic antibacterial effect against salivary $S$. mutans and Lactobacillus sp. combined fluoride and xylitol products are promising agents for prevention of dental caries in children.

\section{References:}

Addy, Martin. 2008. 'Oral Hygiene Products: Potential for Harm to Oral and Systemic Health?' Periodontology $2000 \quad$ 48: 54-65. https://doi.org/10.1111/j.1600-0757.2008.00253.x.

Advani, Shweta, Suma Sogi, Shivayogi Hugar, K. R. Indushekar, K. Kiran, and Seema Hallikerimath. 2014. 'Remineralization Effects of Two Pediatric Dentifrices and One Regular Dentifrice on Artificial Carious Lesion in Primary Teeth: An in Vitro Study'. Journal of International Society of Preventive \& Community Dentistry 4 (2): 96-102. https://doi.org/10.4103/2231-0762.137627.

Akotakar, AM, RR Thenge, AV Patil, AB Ghonge, and MB Bhaltadak. 2018. 'Formulation and Comparative Standardization of Toothpaste'. International Journal of Pharmaceutical Science and Research 3 (4): 12-15.

Alkhateeb, Alaa A., Lloyd A. Mancl, Richard B. Presland, Marilynn L. Rothen, and Donald L. Chi. 2017. 'Unstimulated Saliva-Related Caries Risk Factors in Individuals with Cystic Fibrosis: A CrossSectional Analysis of Unstimulated Salivary Flow, PH, and Buffering Capacity'. Caries Research 51 (1): 1-6. https://doi.org/10.1159/000450658.

Alves, Crésio, Márcia Brandão, Juliana Andion, and Rafaela Menezes. 2010. 'Use of Graduated Syringes for Measuring Salivary Flow Rate: A Pilot Study'. Brazilian Dental Journal 21 (5): 401-4. https://doi.org/10.1590/s0103$\underline{64402010000500004 .}$.

Arnold, Wolfgang H., Andreas Dorow, Stephanie Langenhorst, Zeno Gintner, Jolan Bánóczy, and Peter Gaengler. 2006. 'Effect of Fluoride Toothpastes on Enamel Demineralization'. BMC 
Oral Health 6 (June): 8. https://doi.org/10.1186/1472-6831-6-8.

Baliga, Sharmila, Sangeeta Muglikar, and Rahul Kale. 2013. 'Salivary PH: A Diagnostic Biomarker'. Journal of Indian Society of Periodontology 17 (4): 461-65. https://doi.org/10.4103/0972-124X.118317.

Bhattarai, Kashi Raj, Hyung-Ryong Kim, and HanJung Chae. 2018. 'Compliance with Saliva Collection Protocol in Healthy Volunteers: Strategies for Managing Risk and Errors'. International Journal of Medical Sciences 15 (8): 823-31. https://doi.org/10.7150/ijms.25146.

Bouassida, Mouna, Nada Fourati, Fatma Krichen, Raida Zouari, Semia Ellouz-Chaabouni, and Dhouha Ghribi. 2017. 'Potential Application of Bacillus Subtilis SPB1 Lipopeptides in Toothpaste Formulation'. Journal of Advanced Research 8 (4): 425-33. https://doi.org/10.1016/j.jare.2017.04.002.

Caglar, E., S. C. Kavaloglu, O. O. Kuscu, N. Sandalli, P. L. Holgerson, and S. Twetman. 2007. 'Effect of Chewing Gums Containing Xylitol or Probiotic Bacteria on Salivary Mutans Streptococci and Lactobacilli'. Clinical Oral Investigations 11 (4): 425-29. https://doi.org/10.1007/s00784-0070129-9.

Camara, Danielle Mendes da, Marcela Lumi Miyasaki, Marcelle Danelon, Kikue Takebayashi Sassaki, and Alberto Carlos Botazzo Delbem. 2014. 'Effect of Low-Fluoride Toothpastes Combined with Hexametaphosphate on in Vitro Enamel Demineralization'. Journal of Dentistry 42 (3): 25662. https://doi.org/10.1016/j.jdent.2013.12.002.

Campus, Guglielmo, Maria Rosario Lallai, and Roberto Carboni. 2003. 'Fluoride Concentration in Saliva after Use of Oral Hygiene Products'. Caries Research $\quad 37 \quad$ (1): 66-70. https://doi.org/10.1159/000068220.

Chałas, Renata, Ilona Wójcik-Chęcińska, Michał J. Woźniak, Justyna Grzonka, Wojciech Święszkowski, and Krzysztof J. Kurzydłowski. 2015. 'Dental plaque as a biofilm - a risk in oral cavity and methods to prevent'. Postepy Higieny I Medycyny Doswiadczalnej (Online) 69 (October): 1140-48.

https://doi.org/10.5604/17322693.1173925.

Chandan, G. D., Sweta Saraf, Nagaveni Sangavi, and Anushree Khatri. 2018. 'Pattern of Dental Caries in
3-6-Year-Old Children Using Decayed, Missing, Filled Surface Index and Hierarchical Caries Pattern System: A Descriptive Study'. Journal of the Indian Society of Pedodontics and Preventive Dentistry 36 (2):

108-12.

https://doi.org/10.4103/JISPPD.JISPPD_1183_17.

Chi, Donald L., Ohnmar Tut, and Peter Milgrom. 2014. 'Cluster-Randomized Xylitol Toothpaste Trial for Early Childhood Caries Prevention'. Journal of Dentistry for Children (Chicago, Ill.) 81 (1): 27-32.

Cooper, D. G., and B. G. Goldenberg. 1987. 'Surface-Active Agents from Two Bacillus Species'. Applied and Environmental Microbiology 53

224-29.

https://doi.org/10.1128/AEM.53.2.224-229.1987.

Das, Ishita, Suki Roy, Shreta Chandni, L Karthik, Gaurav Kumar, and K V Bhaskara Rao. 2013. 'Biosurfactant from Marine Actinobacteria and Its Application in Cosmetic Formulation of Toothpaste', 6 .

Den, Rei, Masahiro Toda, Shingo Nagasawa, Kazuyuki Kitamura, and Kanehisa Morimoto. 2007. 'Circadian Rhythm of Human Salivary Chromogranin A'. Biomedical Research (Tokyo, Japan) $\quad 28$ (1): 57-60. https://doi.org/10.2220/biomedres.28.57.

Dentino, Andrew R., Moawia M. Kassab, and Erica J. Renner. 2005. 'Prevention of Periodontal Diseases'. Dental Clinics of North America 49 (3): 573-94, vi. https://doi.org/10.1016/j.cden.2005.03.005.

Elamin, Amal, Malin Garemo, and Andrew Gardner. 2018. 'Dental Caries and Their Association with Socioeconomic Characteristics, Oral Hygiene Practices and Eating Habits among Preschool Children in Abu Dhabi, United Arab Emirates - the NOPLAS Project'. BMC Oral Health 18 (1): 104. https://doi.org/10.1186/s12903-0180557-8.

Esser, Diederik, Gloria Alvarez-Llamas, Marcel P. de Vries, Desiree Weening, Roel J. Vonk, and Han Roelofsen. 2008. 'Sample Stability and Protein Composition of Saliva: Implications for Its Use as a Diagnostic Fluid'. Biomarker Insights 3 (February): 25-27. https://doi.org/10.4137/bmi.s607.

Flink, H., A. Tegelberg, and F. Lagerlöf. 2005. 
'Influence of the Time of Measurement of Unstimulated Human Whole Saliva on the Diagnosis of Hyposalivation'. Archives of Oral Biology 50 (6): 553-59.

https://doi.org/10.1016/j.archoralbio.2004.10.015.

Fraga, Cláudia Perez Trindade, Márcia Pinto Alves Mayer, and Célia Regina Martins Delgado Rodrigues. 2010. 'Use of Chewing Gum Containing $15 \%$ of Xylitol and Reduction in Mutans Streptococci Salivary Levels'. Brazilian Oral Research $24 \quad$ (2): $142-46$. https://doi.org/10.1590/s1806-83242010000200003.

Hayes, C. 2001. 'The Effect of Non-Cariogenic Sweeteners on the Prevention of Dental Caries: A Review of the Evidence'. Journal of Dental Education 65 (10): 1106-9.

Hegde, Rahul J., and Shamika Kamath. 2017. 'Comparison of the Streptococcus Mutans and Lactobacillus Colony Count Changes in Saliva Following Chlorhexidine $(0.12 \%)$ Mouth Rinse, Combination Mouth Rinse, and Green Tea Extract $(0.5 \%)$ Mouth Rinse in Children'. Journal of the Indian Society of Pedodontics and Preventive Dentistry $\quad 35 \quad$ (2): 150-55. https://doi.org/10.4103/JISPPD.JISPPD_13_17.

Hosadurga, Rajesh, Vinita Ashutosh Boloor, Sudharshan N. Rao, and N. MeghRani. 2018. 'Effectiveness of Two Different Herbal Toothpaste Formulations in the Reduction of Plaque and Gingival Inflammation in Patients with Established Gingivitis - A Randomized Controlled Trial'. Journal of Traditional and Complementary Medicine 8 113-19.

https://doi.org/10.1016/j.jtcme.2017.04.005.

Ingle, Navin Anand, Reenu Sirohi, Navpreet Kaur, and Amit Siwach. 2014. 'Salivary Fluoride Levels after Toothbrushing with Dentifrices Containing Different Concentrations of Fluoride'. Journal of International Society of Preventive \& Community Dentistry 4 (2): 129-32. https://doi.org/10.4103/2231-0762.139837.

Jafer, Mohammed, Shankargouda Patil, Jagadish Hosmani, Shilpa H. Bhandi, Elna P. Chalisserry, and Sukumaran Anil. 2016. 'Chemical Plaque Control Strategies in the Prevention of Biofilm-Associated Oral Diseases'. The Journal of Contemporary Dental Practice 17 (4): 337-43. https://doi.org/10.5005/jpjournals-10024-1851.
Janket, Sok-Ja, Jaspreet Benwait, Paul Isaac, Leland K. Ackerson, and Jukka H. Meurman. 2019. 'Oral and Systemic Effects of Xylitol Consumption'. Caries Research 53 (5): 491-501. https://doi.org/10.1159/000499194.

Jing, Chen, Cheng Lei, Zhou Xuedong, and Peng Xian. 2018. 'Recent achievements in the microbiological etiology of dental caries'. Hua Xi Kou Qiang Yi Xue Za Zhi = Huaxi Kouqiang Yixue Zazhi = West China Journal of Stomatology 36 (1): 104-8. https://doi.org/10.7518/hxkq.2018.01.020.

Juri, Hrvoje, and Ivana Ukovi. 2011. 'EFFECTIVENESS OF DIFFERENT PREVENTIVE PROCEDURES IN THE CONTROL OF CARIOGENIC RISK FACTORS IN CHILDREN'. Paediatr Croat 55: 1-6.

K, Yamuna Priya, and Prathibha K. 2021. 'Methods of Collection of Saliva - A Review'. International Journal of Oral Health Dentistry 3 (3): 149-53.

King'ori, A.M. 2011. 'A Review of the Uses of Poultry Eggshells and Shell Membranes'. International Journal Of Poultry Sciences 10 (11): 908-12.

Kumar, Sujay, Sapna Konde, Sunil Raj, and Manisha Agarwal. 2012. 'Effect of Oral Health Education and Fluoridated Dentifrices on the Oral Health Status of Visually Impaired Children'. Contemporary Clinical Dentistry 3 (4): 398-401. https://doi.org/10.4103/0976-237X.107425.

Kuriakose, S., C. Sundaresan, V. Mathai, E. Khosla, and F. M. A. Gaffoor. 2013. 'A Comparative Study of Salivary Buffering Capacity, Flow Rate, Resting $\mathrm{PH}$, and Salivary Immunoglobulin A in Children with Rampant Caries and Caries-Resistant Children'. Journal of the Indian Society of Pedodontics and Preventive Dentistry 31 (2): 6973. https://doi.org/10.4103/0970-4388.115697.

Lagerweij, M. D., and J. M. ten Cate. 2002. 'Remineralisation of Enamel Lesions with Daily Applications of a High-Concentration Fluoride Gel and a Fluoridated Toothpaste: An in Situ Study'. Caries Research 36 (4): 270-74. https://doi.org/10.1159/000063929.

Lippert, Frank. 2013. 'An Introduction to Toothpaste - Its Purpose, History and Ingredients'. Monographs in Oral Science 23: 1-14. 
https://doi.org/10.1159/000350456.

Mäkinen, Kauko K. 2010. 'Sugar Alcohols, Caries Incidence, and Remineralization of Caries Lesions: A Literature Review'. International Journal of Dentistry 2010: 981072. https://doi.org/10.1155/2010/981072.

Mäkinen, Kauko K., Pentti Alanen, Pauli Isokangas, Kauko Isotupa, Eva Söderling, Pirkko-Liisa Mäkinen, Wang Wenhui, et al. 2008. 'Thirty-NineMonth Xylitol Chewing-Gum Programme in Initially 8-Year-Old School Children: A Feasibility Study Focusing on Mutans Streptococci and Lactobacilli'. International Dental Journal 58 (1): 41-50. https://doi.org/10.1111/j.1875-

595x.2008.tb00175.x.

Malhotra, Ritika, Shilpy Singla, and N. D. Shashikiran. 2017. 'Comparison of Antimicrobial Activity of Child Formula Dentifrices at Different Concentrations: An in Vitro Study'. International Journal of Clinical Pediatric Dentistry 10 (2): 13135. https://doi.org/10.5005/jp-journals-10005-1422.

Mangilal, T., and M. Ravikumar. 2016. 'Preparation And Evaluation Of Herbal Toothpaste And Compared With Commercial Herbal Toothpastes: An Invitro Study'. 2016. /paper/Preparation-AndEvaluation-Of-Herbal-Toothpaste-And-MangilalRavikumar/8df9af6c17960eefc6c56fb0af5bb65cc42 c8895.

Marsh, Philip D. 2006. 'Dental Plaque as a Biofilm and a Microbial Community - Implications for Health and Disease'. BMC Oral Health 6 Suppl 1 (June): S14. https://doi.org/10.1186/1472-6831-6$\underline{\mathrm{S} 1-\mathrm{S} 14 .}$.

Muller-Bolla, Michèle, and Frédéric Courson. 2013. 'Toothbrushing Methods to Use in Children: A Systematic Review'. Oral Health \& Preventive Dentistry $11 \quad$ (4): $341-47$. https://doi.org/10.3290/j.ohpd.a30602.

Muralikrishnan, K, S Asokan, and PR Priya. 2018. 'Effect of Different Chewing Gums on Dental Plaque $\mathrm{PH}$, Salivary $\mathrm{PH}$, and Buffering Capacity in Children: A Randomized Controlled Trial'. SRM J Res Dent Sci 9 (4): 113-17.

Navazesh, Mahvash, Satish K. S. Kumar, and University of Southern California School of Dentistry. 2008. 'Measuring Salivary Flow:
Challenges and Opportunities'. Journal of the American Dental Association (1939) 139 Suppl (May): $35 \mathrm{~S}-40 \mathrm{~S}$. https://doi.org/10.14219/jada.archive.2008.0353.

Oza, Swapnil, Kreta Patel, Satish Bhosale, Ruchi Mitra, Rupam Gupta, and Divya Choudhary. 2018. 'To Determine the Effect of Chewing Gum Containing Xylitol and Sorbitol on Mutans Streptococci and Lactobacilli Count in Saliva, Plaque, and Gingival Health and to Compare the Efficacy of Chewing Gums'. Journal of International Society of Preventive \& Community Dentistry $\quad 8 \quad$ (4): $\quad 354-60$. https://doi.org/10.4103/jispcd.JISPCD $54 \quad 18$.

Pancu, Galina, Sorin Andrian, Simona Stoleriu, Angela Gheorghe, Irina Nica, Claudiu Topoliceanu, Moldovanu Antonia, Nicoleta Tofan, and Gianina Iovan. 2017. 'THE EFFECT OF XYLITOLBASED ORAL HYGIENE PRODUCTS ON SALIVA PARAMETERS AND BACTERIAL BIOFILM CARIOACTIVITY' 9 (2): 7.

Petersen, Poul Erik. 2004. 'Continuous improvement of oral health in the 21 st century: the approach of the WHO Global Oral Health Programme'. Zhonghua Kou Qiang Yi Xue Za Zhi= Zhonghua Kouqiang Yixue Zazhi = Chinese Journal of Stomatology 39 (6): 441-44.

Pinar Erdem, Arzu, Elif Sepet, Güven Kulekci, Sule Can Trosola, and Yegane Guven. 2012. 'Effects of Two Fluoride Varnishes and One Fluoride/Chlorhexidine Varnish on Streptococcus Mutans and Streptococcus Sobrinus Biofilm Formation in Vitro'. International Journal of Medical Sciences 9 (2): 129-36. https://doi.org/10.7150/ijms.3637.

Resende, Ana Helena M., Juliana M. Farias, Dhanilo D. B. Silva, Raquel D. Rufino, Juliana M. Luna, Thayza Christina M. Stamford, and Leonie A. Sarubbo. 2019. 'Application of Biosurfactants and Chitosan in Toothpaste Formulation'. Colloids and Surfaces. B, Biointerfaces 181 (September): 77-84. https://doi.org/10.1016/j.colsurfb.2019.05.032.

Sabri, Diana, Mohamed Farag, Shadeed Abdelrahman, and Shaimaa Omer. 2020. 'Clinical and Microbiological Effectiveness of Chlorhexidine and Sodium Hexametaphosphate Mouth Rinses on Dental Plaque in Children.' Egyptian Dental Journal 66 (2): 767-80. 
https://doi.org/10.21608/edj.2020.26736.1091.

Sanz, Mariano, Jorge Serrano, Margarita Iniesta, Isabel Santa Cruz, and David Herrera. 2013. 'Antiplaque and Antigingivitis Toothpastes'. Monographs in Oral Science 23: 27-44. https://doi.org/10.1159/000350465.

Sawair, Faleh A., Soukaina Ryalat, Mohammad Shayyab, and Takashi Saku. 2009. 'The Unstimulated Salivary Flow Rate in a Jordanian Healthy Adult Population'. Journal of Clinical Medicine Research 1 (4): 219-25. https://doi.org/10.4021/jocmr2009.10.1267.

Shwetha, R, and S Vivek. 2017. 'Effect of Dentifrices Containing Sorbitol, Combination of Xylitol and Sorbitol on Salivary Streptococcus Mutans and Lactobacillus Counts in 14-15 Year Old Children: A Randomized Trial'. International Journal of Clinical Trials 4 (4): 184-90. https://doi.org/10.18203/2349-3259.ijct20174865.

Simratvir, M., G. A. Moghe, A. M. Thomas, N. Singh, and S. Chopra. 2009. 'Evaluation of Caries Experience in 3-6-Year-Old Children, and Dental Attitudes amongst the Caregivers in the Ludhiana City'. Journal of the Indian Society of Pedodontics and Preventive Dentistry 27 (3): 164-69. https://doi.org/10.4103/0970-4388.57097.

Sotthipoka, Kanyapak, Pintusorn Thanomsuk,
Rungroj Prasopsuk, Chutima Trairatvorakul, and Kasekarn Kasevayuth. 2018. 'The Effects of Toothpaste Amounts and Post-Brushing Rinsing Methods on Salivary Fluoride Retention'. Journal of Health Research 32 (6): 421-31. https://doi.org/10.1108/JHR-11-2018-082.

Souza, Daniela Correia Cavalcante, Marisa Maltz, and Lina Naomi Hashizume. 2014. 'Fluoride Retention in Saliva and in Dental Biofilm after Different Home-Use Fluoride Treatments'. Brazilian Oral Research 28. https://doi.org/10.1590/1807-3107bor2014.vol28.0039.

Van Loveren, C. 2004. 'Sugar Alcohols: What Is the Evidence for Caries-Preventive and CariesTherapeutic Effects?' Caries Research 38 (3): 28693. https://doi.org/10.1159/000077768.

Wu, Katie P., Jyh-Yuh Ke, Chia-Ying Chung, ChiaLing Chen, Tsong-Long Hwang, Ming-Yen Chou, Alice M. K. Wong, Ching-Fang Hu, and Yu-Cheng Lee. 2008. 'Relationship between Unstimulated Salivary Flow Rate and Saliva Composition of Healthy Children in Taiwan'. Chang Gung Medical Journal 31 (3): 281-86.

Yoshihara, A., S. Sakuma, S. Kobayashi, and H. Miyazaki. 2001. 'Antimicrobial Effect of Fluoride Mouthrinse on Mutans Streptococci and Lactobacilli in Saliva'. Pediatric Dentistry 23 (2): 113-17. 